\title{
Analisa Postur Kerja Operator Pada UD. Kenari Bakeri Menggunakan Metode Quick Exposure Check (QEC)
}

\author{
Faradila Ananda Yul, Indah Sari Nasution \\ Program Studi Teknik Industri, Fakultas Teknik \\ Universitas Muhammadiyah Riau \\ Jl. Tuanku Tambusai Ujung - Pekanbaru \\ E-mail: faradilaay@gmail.com
}

\begin{abstract}
Abstrak
UD. Kenari Bakeri merupakan Usaha Kecil Menengah yang memproduksi kue dan roti. Sebagian besar aktivitas pada UD. Kenari Bakeri dilakukan secara manual seperti: membulatkan adonan roti, mencetak roti dan pemberian toping roti. Aktivitas-aktivitas tersebut dilakukan pada sebuah meja kerja yang berukuran $150 \mathrm{~cm}$ x $100 \mathrm{~cm}$ x $72 \mathrm{~cm}$, Tinggi meja tersebut relatif lebih rendah dibandingkan dengan tinggi operator yaitu pada rentang $156-168 \mathrm{~cm}$. Kondisi ini menyebabkan operator cenderung membungkuk pada saat melakukan pekerjaan sehingga operator sering mengeluh merasakan sakit pada punggung dan leher mereka. Penelitian ini bertujuan untuk menganalisa postur kerja operator UD. Kenari Bakeri dalam melakukan pekerjaan. Hasil penelitian ini menunjukan bahwa exsposure score operator yakni $88.06 \%$. Nilai ini berada pada exposure level yang tinggi yaitu $\geq 70 \%$ menunjukan bahwa postur kerja operator pada UD. Kenari Bakeri sangat berisiko terjadi cidera akibat kerja apabila dilakukan secara terus menerus.
\end{abstract}

Kata kunci : Postur Kerja, Exposure score, Exposure Level

\begin{abstract}
UD. Kenari Bakeri is small and medium enterprise that produce cakes and breads. Most of the action at UD. Kenari Bakeri done manually such as: rounding the bread dough, bread, and provision of print toping bread. The activities are carried out on a work table measuring $150 \mathrm{~cm} \times 100 \mathrm{~cm} \times 72 \mathrm{~cm}$, Height of the table is relatively lower compared to the high operator is in the range of $156-168 \mathrm{~cm}$. This condition causes the operator tends bent upon doing so the operators often complain of pain in their back and neck. This study aims to analyze the posture of the operator at UD. Kenari Bakeri in doing the job. These results indicate that the operator exsposure score of $88.06 \%$. This value is at a high level exposure is $\geq$ $70 \%$ indicates that the posture of the operator at UD. Walnuts are very risky Bakeri an injury caused by work, if done continuously.
\end{abstract}

Keywords : Work Posture, Exposure score, Exposure Level

\section{Pendahuluan}

Kondisi pekerja sangat mempengaruhi produktifitas dari pekerja pada sebuah perusahaan. Untuk mewujudkan hal tersebut sangat dibutuhkan kondisi kerja yang efektif, nyaman, aman, sehat dan efesien. Kondisi kerja yang tidak nyaman selaian dapat mempengaruhi kulitas pekerja saat bekerja juga dapat menyebabkan cedera pada pekerjanya. Saat ini Masih banyak perusahaan yang belum memperhatikan kesehatan pekerja dalam melaksanakan pekerjaan.
UD. Kenari Bakeri merupakan Usaha Kecil Menengah yang memproduksi kue dan roti. UD. Kenari Bakeri melakukan aktivitas produksi selama 4 jam setiap hari dimana sebagian besar aktivitas tersebut dilakukan secara manual pada seperti: membulatkan adonan roti, mencetak roti dan pemberian toping roti. Aktivitas-aktivitas tersebut dilakukan pada sebuah meja kerja yang berukuran $150 \mathrm{~cm}$ x $100 \mathrm{~cm}$ x $72 \mathrm{~cm}$, Tinggi meja tersebut relatif lebih rendah dibandingkan dengan tinggi operator yaitu pada rentang 156 $168 \mathrm{~cm}$. Kondisi ini menyebabkan operator cenderung membungkuk pada saat melakukan 
pekerjaan sehingga operator sering mengeluh merasakan sakit pada punggung dan leher mereka.

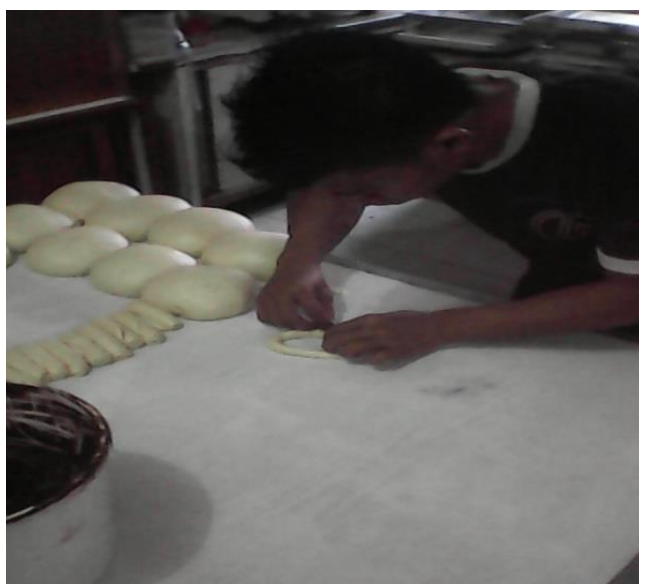

Gambar 1. Postur kerja operator pada kegiatan membulatkan roti

Untuk itu perlu dilakukan penilaian pada postur kerja operator di UD. Kenari Bakeri.

Ergonomi adalah ilmu yang mempelajari manusia sebagai komponen dari suatu sistem kerja mencakup karakteristik fisik maupun nonfisik, keterbatasan manusia, dan kemampuannya dalam rangka merancang suatu sistem yang efektif, aman, sehat, nyaman, dan efisien. Ergonomi dalam rancangan fasilitas kerja adalah merupakan faktor penting dalam menunjang peningkatan pelayanan jasa produksi. Terutama dalam hal perancangan ruang dan sarana. Perlunya memperhatikan faktor ergonomi dalam proses rancang bangun fasilitas ini merupakan sesuatu yang tidak dapat dipungkiri lagi masalah ergonomi sangat erat kaitannya dengan alat, aktivitas, serta produk yang dihasilkan oleh manusia. Permasalahan yang berkaitan dengan faktor ergonomi umumnya disebabkan oleh adanya ketidaksesuaian antara pekerja dan lingkungan kerja secara menyeluruh termasuk peralatan kerja . (Indah dkk,2014).

Quick Exposure Check (QEC) merupakan salah satu metode yang dapat digunakan untuk mengetahui risiko cidera gangguan otot rangka (musculoskeletal disorder) yang menitik beratkan pada tubuh bagian atas yaitu punggung, leher, lengan/bahu, dan pergelangan tangan. Kelebihan dari metode ini adalah mempertimbangkan kondisi yang dialami oleh pekerja dari dua sudut pandang yaitu dari sudut pandang pengamat dan juga operator itu sendiri. Hal ini dapat memperkecil bias penilaian subjektif dari pengamat (Ilham Dkk, 2013).
Untuk perhitungan nilai Exposure (E) sebagai berikut ini:

$$
\mathrm{E}(\%)=\frac{\mathrm{x}}{\mathrm{x} \max } \times 100 \%
$$

$$
\begin{aligned}
& \mathrm{X}= \text { Total skor yang didapat untuk } \\
& \begin{array}{c}
\text { paparan risiko cedera untuk } \\
\text { punggung, }
\end{array} \\
& \text { bahu/lengan, }
\end{aligned}
$$
pergelangan tangan, dan leher yang diperoleh dari perhitungan kuesioner.

$\mathrm{Xmax}=$ Total maksimum skor untuk paparan yang mungkin terjadi untuk punggung, bahu/lengan, pergelangan tangan, dan leher.

Nilai exposure level yang didapat untuk menentukan tindakan apa yang dilakukan berdasarkan dari hasil perhitungan total exposure score. Tindakan yang harus diambil berdasarkan nilai yang dihasilkan dalam perhitungan exposure level dapat dilihat pada Tabel dibawah ini :

Tabel 1.

Action Level QEC

\begin{tabular}{|c|c|}
\hline Total Eksposure Level & Action \\
\hline$<40 \%$ & Aman \\
\hline $40-49 \%$ & Perm penelitian kbih lanjut \\
\hline $50-69 \%$ & Perm penelitian lebih lanjut dan tindakan lanjut \\
\hline$\geq 70 \%$ & Dilaknkan penelition dan pernbahan selanjutnya \\
\hline
\end{tabular}

\section{Methodologi}

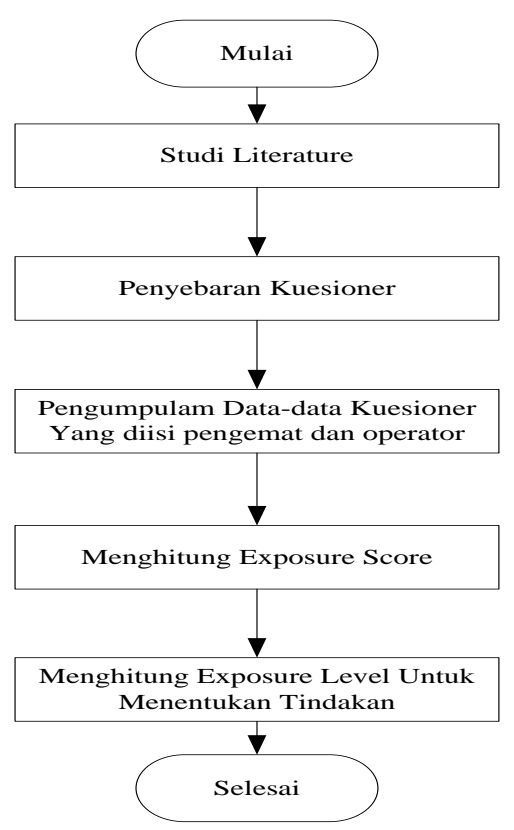

Gambar 2. Flowchart penelitian 


\section{Hasil dan Pembahasan}

Penilaian yang dilakukan berdasarkan kuisioner yang terlampir kepada pengamat dan operator, Adapun hal-hal yang dinilai dapat dilihat pada tabel 2. sebagai berikut :

Tabel 2.

Penilaian Pengamat dan Operator

\begin{tabular}{|c|c|c|c|c|c|c|}
\hline FAKTOR & KODE & 1 & 2 & 3 & 4 & 5 \\
\hline PUNGGUNG & $\mathbf{A}$ & \begin{tabular}{|c|} 
Hampir \\
lurus
\end{tabular} & Agak & Tertahu & & \\
\hline \begin{tabular}{|l|} 
MENDORONG/ \\
MENARIK \\
\end{tabular} & B & Tidak & Iya & 3 kali & 8 kali & lebih 12 kali \\
\hline BAHU & C & \begin{tabular}{|c|} 
Sekitar \\
pinggang
\end{tabular} & $\begin{array}{c}\text { Sekitar } \\
\text { dada }\end{array}$ & $\begin{array}{c}\text { Sekitar } \\
\text { bahu }\end{array}$ & & \\
\hline LENGAN & D & Jarang & Sering & $\begin{array}{l}\text { Sangat } \\
\text { sering } \\
\end{array}$ & & \\
\hline $\begin{array}{l}\text { PERGELLANGAN } \\
\text { TANGAN }\end{array}$ & E & $\begin{array}{c}\text { Hampir } \\
\text { lurus }\end{array}$ & Tertekuk & & & \\
\hline TANGAN & $\mathbf{F}$ & $10 \mathrm{kali}$ & 11-20 kali & $\begin{array}{c}\text { Lebih } 20 \\
\text { kali }\end{array}$ & & \\
\hline LEHER & G & Tidak & Terkadang & \begin{tabular}{|c|} 
Terus- \\
menerus \\
\end{tabular} & & \\
\hline BEBAN & $\mathrm{H}$ & Ringan & Cukup & Berat & $\begin{array}{c}\text { Sangat } \\
\text { berat }\end{array}$ & \\
\hline DURASI & I & $\begin{array}{c}\text { Kurang } 2 \\
\text { jam }\end{array}$ & 2-4 jam & \begin{tabular}{|c|} 
Lebih 4 \\
jam
\end{tabular} & & \\
\hline $\begin{array}{l}\text { KEKUATAN } \\
\text { TANGAN }\end{array}$ & $\mathbf{J}$ & Rendah & sedang & tinggi & & \\
\hline VISUAL & $\mathrm{K}$ & Rendah & tinggi & & & \\
\hline \begin{tabular}{|l|} 
PENGGUNAAN \\
KENDARAAN \\
\end{tabular} & $\mathrm{L}$ & \begin{tabular}{|l|} 
Tidak \\
Pernah \\
\end{tabular} & 1-4 jam & \begin{tabular}{|c|}
$\begin{array}{c}\text { Lebih } 4 \\
\text { jam }\end{array}$ \\
\end{tabular} & & \\
\hline GETARAN & $\mathbf{M}$ & $\begin{array}{l}\text { Tidak } \\
\text { Pernah } \\
\end{array}$ & 1-4 jam & $\begin{array}{c}\text { Lebih } 4 \\
\text { jam }\end{array}$ & & \\
\hline \begin{tabular}{|l|} 
TINGKAT \\
KESULITAN \\
\end{tabular} & $\mathrm{N}$ & $\begin{array}{l}\text { Tidak } \\
\text { Pernahh } \\
\end{array}$ & Terkadang & Sering & & \\
\hline TINGKAT STRES & $\mathbf{0}$ & $\begin{array}{l}\text { Tidak } \\
\text { stres }\end{array}$ & $\begin{array}{l}\text { Cukup } \\
\text { Stres }\end{array}$ & Stres & $\begin{array}{c}\text { Sangat } \\
\text { Stres }\end{array}$ & \\
\hline
\end{tabular}

\subsection{Perhitungan Exposure Score}

Adapun hasil kuesioner dari pengamat dan operator pada table 3 dan 4 .

Tabel 3.

Rekapitulasi Hasil Pengamat

\begin{tabular}{|c|c|l|l|c|c|c|c|c|c|c|}
\hline Stasiun Kerja & Oprator & Nama oprator & A & B & B & C & D & E & F & G \\
\hline pencetakan roti & 1 & Didi Supardi & A3 & B2 & B4 & Cl & D3 & E2 & F3 & G3 \\
\hline pencetakan roti & 2 & Andi & A3 & B2 & B4 & Cl & D3 & E2 & F3 & G3 \\
\hline pencetakan roti & 3 & Boy Mansir & A3 & B2 & B4 & Cl & D3 & E2 & F2 & G3 \\
\hline pencetakan roti & 4 & Dewi & A3 & B2 & B5 & Cl & D3 & E2 & F2 & G3 \\
\hline pencetakan roti & 5 & Dani & A3 & B2 & B4 & C1 & D3 & E2 & F2 & G3 \\
\hline pencetakan roti & 6 & Susi & A3 & B2 & B5 & Cl & D3 & E2 & F3 & G3 \\
\hline pencetakan roti & 7 & Jufia & A3 & B2 & B5 & C1 & D3 & E2 & F2 & G3 \\
\hline pencetakan roti & 8 & Agus & A3 & B2 & B4 & Cl & D3 & E2 & F3 & G3 \\
\hline pencetakan roti & 9 & Intan & A3 & B2 & B4 & Cl & D3 & E2 & F3 & G3 \\
\hline pencetakan roti & 10 & Yulianti & A3 & B2 & B4 & Cl & D3 & E2 & F3 & G3 \\
\hline
\end{tabular}

Perhitungan dilakukan pada lembar skor QEC seperti tampak pada Gambar 3.
Tabel 4.

Rekapitulasi Hasil Operator

\begin{tabular}{|c|c|c|c|c|c|c|c|c|c|c|}
\hline Stasiun Kerja & Oprator & Nama Oprato & $\mathrm{H}$ & I & $\mathrm{J}$ & $\mathrm{K}$ & L & M & $\mathrm{N}$ & 0 \\
\hline encetalan roti & 1 & Didi Supardi & $\mathrm{H3}$ & I3 & $\sqrt{2}$ & $\mathrm{~K} 2$ & L1 & Ml & $\mathrm{N} 2$ & 02 \\
\hline encetakan roi & 2 & Andi & $\mathrm{H} 2$ & I3 & $\sqrt{2}$ & $\mathbf{K} 2$ & L1 & Ml & $\mathrm{N} 2$ & 02 \\
\hline ancetakan roti & 3 & Boy Mansur & $\mathrm{H} 2$ & I3 & $\sqrt{2}$ & $\mathrm{~K} 2$ & L1 & Ml & $\mathrm{N} 2$ & 02 \\
\hline noetaken roti & 4 & Dewi & $\mathrm{H} 2$ & I3 & $\sqrt{2}$ & K2 & L1 & Ml & N2 & 02 \\
\hline encetakan roti & 5 & Dani & $\mathrm{H} 2$ & I3 & $\sqrt{2}$ & $\mathbf{K} 2$ & L1 & Ml & N2 & 02 \\
\hline encetakan roti & 6 & Sisi & $\mathrm{H} 2$ & 13 & $\sqrt{2}$ & K2 & L1 & Ml & $\mathrm{N} 2$ & 02 \\
\hline cencetakan roti & 7 & Julin & $\mathrm{Hl}$ & I3 & $\sqrt{2}$ & K2 & L1 & Ml & N2 & 02 \\
\hline pencetakan roti & 8 & Aqus & $\mathrm{H} 2$ & I3 & $\sqrt{2}$ & K2 & L1 & Ml & N2 & 02 \\
\hline encetakan roti & 9 & Intan & $\mathrm{H} 2$ & I3 & $\sqrt{2}$ & $\mathbf{K} 2$ & L1 & Ml & $\mathrm{N} 2$ & 02 \\
\hline noetakan roti & 10 & Yulfanti & $\mathrm{H} 2$ & I3 & $\sqrt{2}$ & K2 & L1 & Ml & $\mathrm{N} 2$ & 02 \\
\hline
\end{tabular}

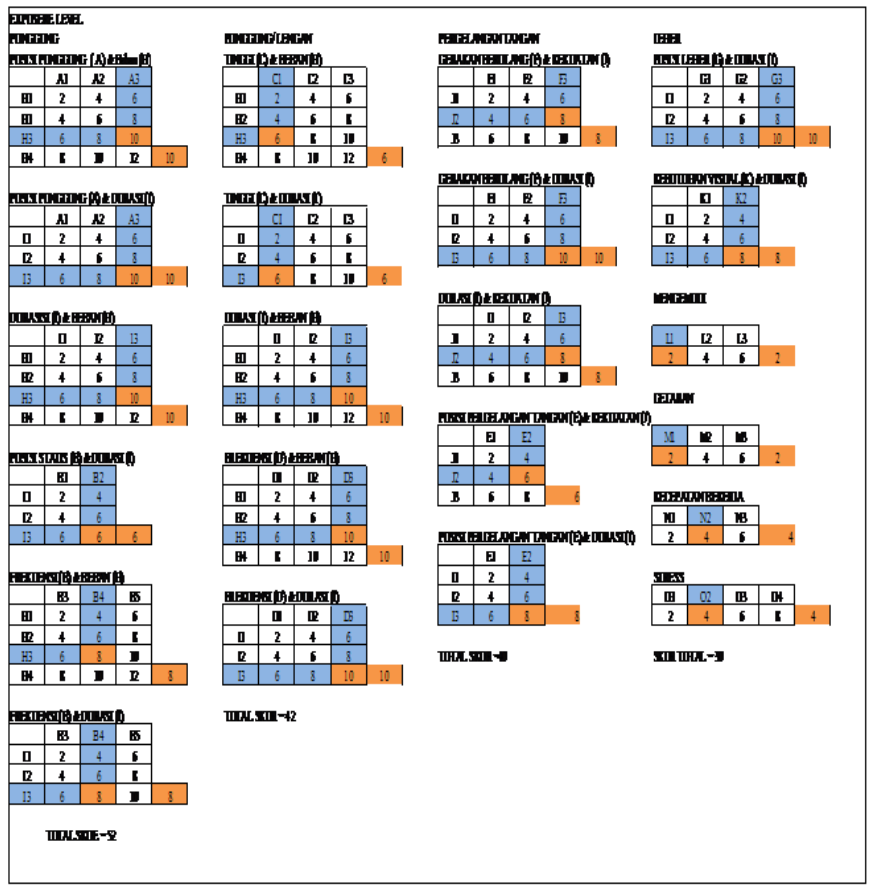

Gambar 3. Perhitungan Aktual exposure

\subsection{Hasil Exposure Score}

Hasil dari jawaban pada QEC dapat dilihat pada tabel 5.

Tabel 5.

Hasil Exposure Score

\begin{tabular}{|c|c|c|c|c|c|c|c|c|c|c|c|}
\hline $\begin{array}{l}\text { Angyota Thtoh Yang } \\
\text { Diamati } \\
\end{array}$ & OP 1 & $\mathrm{OP} 2$ & OP3 & OP 4 & OP 5 & OP 6 & & & $\mathrm{OP}$ & $\mathrm{OP} 1$ & tatratate \\
\hline Puggung & 56 & 46 & 52 & 38 & 52 & 56 & 44 & 46 & 46 & 46 & 48,2 \\
\hline Bahl/Legan & 42 & 38 & 38 & 38 & 38 & \begin{tabular}{|l|}
42 \\
\end{tabular} & 34 & 38 & 38 & 38 & 38,4 \\
\hline pergehngan Tan & 40 & 40 & 36 & 36 & $36 \mid$ & 40 & 36 & 40 & 40 & 40 & 38,4 \\
\hline Lether & 30 & 30 & 30 & 30 & 30 & 30 & 30 & 30 & 30 & 30 & 30 \\
\hline total & 168 & 154 & 156 & 142 & 156 & 168 & 144 & 154 & 154 & 154 & 155 \\
\hline dal Raltr-nat & & & & & & & & & & & 155 \\
\hline
\end{tabular}

\subsection{Perhitungan Nilai Action Level QEC}

Untuk mengetahui tindakan yang akan kita lakukan pada pekerja kita perlu melakukan perhitungan dan melihat pada tabel Action Level 
QEC yang ada pada Tabel 5. Nilai Action Level $Q E C$ dapat dihitungkan sebagai berikut:

$$
\begin{aligned}
\mathrm{E}(\%) & =\frac{155}{176} \times 100 \% \\
& =88,06 \%
\end{aligned}
$$

Nilai action level $Q E C$ diperoleh $88,06 \%$, jika dibandingkan batas eksposure level pada tabel 3, maka postur kerja tersebut dikatakan beresiko akan terjadi sakit pada tulang belakang sehingga harus diubah secepatnya.

\section{Simpulan}

Berdasarkan pengolahan data dan pembahasan analisa pada penelitian ini maka kesimpulan dari penelitian telah dilakukan pada UD. Keneri bakeri dari 10 orang operator dengan Metode Quik Exposure Check (QEC) mendapatkan hasil dengan level tindakan yang tinggi yaitu $88,06 \%$ dimana ini berada pada exposure level $\geq 70 \%$ sehingga sangat berisiko terjadi cidera pada operator pada saat bekerja.

\section{Daftar Pustaka}

[1] Budi, Dkk. Laporan Analisa Perancangan Kerja, Universitas Muhammadiyah Riau. 2013

[2] Ezi, Dkk. Usulan Perbaikan Stasiun Kerja pada PT. Sinar Advertama Servicindo (SAS) Berdasarkan Hasil Evaluasi Menggunakan Metode Quick Exposure Check (QEC), Institut Teknologi Bandung. 2014

[3] Ilham, Dkk. Rancangan Perbaikan Sistem Kerja dengan Metode Quick Exposure Check (QEC) di Bengkel Sepatu X di Cibaduyut, Istitut Teknologi Bandung. 2013

[4] Indah, Dkk. Pengukuran dan Perancangan kerja dua, Universitas Muhammadiyah Riau. 2015

[5] Sutalaksana, Iftikar Z. Teknik Tata Cara Kerja, Penerbit Jurusan Teknik Industri ITB. 1997

[6] Tarwaka, dkk. Ergonomi Untuk Keselamatan, Kesehatan Kerja dan Produktivitas, UNIBA PRESS, Cetakan pertama, Surakarta. 2004

[7] Julian P. Analisa Beban Kerja Mental dengan Menggunakan Metode Nasa TLX Pada Proses Pengecoran Logam, Universitas Muhammadiyah Riau. 2016
[8] Wignjosoebroto, Sritomo. Ergonomi Studi Gerak dan Waktu, Jurusan Teknik Industri ITS, Surabaya. 2006 